\title{
PENGARUH PEMBELAJARAN BRAIN BASED LEARNING BERBANTUAN MACROMEDIA FLASH TERHADAP PENINGKATAN KEMAMPUAN KOMUNIKASI MATEMATIS SISWA
}

\author{
Resa Sukma Fauzia', Wahyudin ${ }^{2}$, Lala Nailah Zamnah ${ }^{3}$ \\ 1,2,3 Program Studi Pendidikan Matematika, Universitas Galuh, J. R. E. Martadinata No.150, Ciamis, Indonesia \\ Email: resasukmafauzia@gmail.com
}

\begin{abstract}
This study aims to describe the effect of Macromedia Flash-Assisted Brain Based Learning on improving students' mathematical communication skills. The research method used is a quasi-experimental research design with The Nonequivalent Pretest-Posttest Control Group Design. The population in this study were all seventh-grade students. The samples in this study were students of class VIIB as an experimental class with Brain Based Learning learning assisted by Macromedia Flash and class VIIA as a control class with conventional learning. The sampling technique was carried out by purposive sampling. The instrument in this study is a test instrument in the form of a mathematical communication ability test. Data analysis was carried out on the $\mathrm{N}$-gain data using the $t^{\prime}$ test. The results showed that the difference in the effect of Macromedia Flash-assisted Brain Based Learning and conventional learning on increasing students' mathematical communication skills and based on the average, Macromedia Flash-assisted Brain Based Learning had a higher effect on increasing students' mathematical communication skills than conventional learning.
\end{abstract}

Keywords: Brain Based Learning, Komunikasi Matematis, Macromedia Flash

\begin{abstract}
ABSTRAK
Penelitian ini bertujuan untuk mendeskripsikan pengaruh pembelajaran Brain Based Learning berbantuan Macromedia Flash terhadap peningkatan kemampuan komunikasi matematis siswa. Metode penelitian yang digunakan adalah quasi experimental dengan desain penelitian The Nonequivalent Pretest-Posttest Control Group Design. Populasi dalam penelitian ini adalah seluruh siswa kelas VII. Sampel pada penelitian ini adalah siswa kelas VIIB sebagai kelas eksperimen dengan pembelajaran Brain Based Learning berbantuan Macromedia Flash dan kelas VIIA sebagai kelas kontrol dengan pembelajaran konvensional. Teknik pengambilan sampel dilakukan secara purposive sampling. Instrumen pada penelitian ini adalah instrumen tes berupa tes kemampuan komunikasi matematis. Analisis data dilakukan terhadap data N-gain dengan menggunakan uji t'. Hasil penelitian menunjukkan bahwa terdapat perbedaan pengaruh pembelajaran Brain Based Learning berbantuan Macromedia Flash dan pembelajaran konvensional terhadap peningkatan kemampuan komunikasi matematis siswa dan berdasarkan rataratanya, pembelajaran Brain Based Learning berbantuan Macromedia Flash berpengaruh lebih tinggi terhadap peningkatan kemampuan komunikasi matematis siswa daripada pembelajaran konvensional.
\end{abstract}

Kata Kunci: Brain Based Learning, Komunikasi Matematis, Macromedia Flash

Cara sitasi: Fauzia, R. S., Wahyudin., \& Zamnah, L. N. (2021). Pengaruh Pembelajaran Brain Based Learning Berbantuan Macromedia Flash terhadap Peningkatan Kemampuan Komunikasi Matematis Siswa. J-KIP (Jurnal Keguruan dan IImu Pendidikan), 2(3), 103-110. 


\section{PENDAHULUAN}

Permendikbud No. 58 Tahun 2014 Tentang Kurikulum 2013 SMP/MTs menyatakan bahwa salah satu tujuan pembelajaran matematika di sekolah adalah agar siswa memiliki kemampuan mengomunikasikan gagasan, penalaran serta mampu menyusun bukti matematika dengan menggunakan kalimat lengkap, simbol, tabel, diagram, atau media lain untuk memperjelas keadaan atau masalah. Selain itu, komunikasi merupakan salah satu pengalaman belajar yang harus dialami siswa dalam proses pembelajaran pada setiap mata pelajaran (Permendikbud Nomor 81A, 2013).

NCTM (Muslimahayati, 2019) mengungkapkan bahwa Kemampuan komunikasi matematika merupakan kemampuan siswa menggunakan matematika sebagai alat komunikasi (bahasa matematika), dan kemampuan siswa mengomunikasikan matematika yang dipelajari sebagai isi pesan yang harus disampaikan. Kemampuan komunikasi matematis adalah kemampuan untuk mengomunikasikan ide matematika kepada orang lain baik secara lisan, tulisan, ataupun dalam bentuk diagram dan gambar agar orang lain dapat paham dari apa yang kita sampaikan (Saparudin \& Effendi, 2019).

Baroody (Deswita \& Kusumah, 2018) menyebutkan sedikitnya ada dua alasan penting, mengapa komunikasi dalam pembelajaran matematika perlu ditumbuhkembangkan dikalangan siswa, diantaranya: matematika tidak hanya sekadar alat bantu berpikir, alat bantu menemukan pola, menyelesaikan masalah atau mengambil kesimpulan, tetapi matematika juga sebagai aktivitas sosial dalam pembelajaran; matematika sebagai wahana interaksi antar siswa dan juga antar guru dan siswa. Hal ini menunjukkan bahwa komunikasi matematis merupakan salah satu kemampuan penting yang harus dikembangkan dalam diri siswa.

Kemampuan komunikasi matematis merupakan bagian yang sangat penting dalam menyukseskan proses pembelajaran matematika. Tanpa komunikasi, maka proses pembelajaran akan terhambat (Muslimahayati, 2019). Pentingnya kemampuan komunikasi matematis juga diungkap Sumarmo (Deswita \& Kusumah, 2018) bahwa komunikasi matematis merupakan komponen penting dalam belajar matematika, alat untuk bertukar ide, dan mengklarifikasi.

Menurut Sumarno (Hendriana, 2018) ada beberapa indikator untuk mengukur kemampuan komunikasi matematis antara lain (1) menghubungkan benda nyata, gambar, dan diagram ke dalam ide/konsep matematika, (2) menjelaskan ide, situasi, dan relasi matematika secara lisan atau tulisan dengan benda nyata, gambar, grafik, atau bentuk aljabar, (3) menyatakan peristiwa sehari-hari dengan simbol matematika, (4) mendengarkan, berdiskusi, dan menulis tentang matematika, (5) membaca presentasi matematika tertulis dan menyusun pertanyaan yang relevan, (6) membuat konjektur, menyusun argument, merumuskan definisi dan generalisasi.

WHO menetapkan semenjak 30 Januari 2020 sebagai darurat kesehatan berskala global terkait wabah COVID-19. Sejak diumumkannya kasus pertama COVID-19 di Indonesia pada 2 Maret 2020 lalu, jumlah kasus positif Corona terus bertambah setiap harinya. Situasi pandemi COVID-19 telah membuat proses pembelajaran di Indonesia mengalami hambatan terutama dalam pembelajaran matematika.

Dengan adanya instruksi untuk social distancing atau physical distancing dalam rangka memutus rantai penyebaran COVID-19, hampir semua kegiatan pembelajaran dan kegiatan yang sifatnya administratif dikerjakan secara jarak jauh. Pembelajaran dari rumah menuntut guru dan siswa untuk melaksanakan pembelajaran dengan memanfaatkan media digital dan internet. Pada masa ini, teknologi sangat diperlukan dalam kehidupan sehari-hari termasuk dalam pembelajaran matematika.

Pada masa pandemi COVID-19 saat ini, kemajuan teknologi sudah berkembang dengan pesat. Teknologi merupakan salah satu solusi untuk meningkatkan keaktifan dan kreativitas guru. Proses pembelajaran dari rumah menjadikan media digital dan internet menjadi jalan utama bagi guru dan siswa dalam melaksanakan pembelajaran matematika. Sehingga, komunikasi antara guru dengan siswa tetap berjalan. Menggunakan teknologi dalam proses pembelajaran mempunyai kelebihan, yakni mempermudah dan mempercepat kerja siswa, juga menyenangkan karena siswa berinteraksi dengan warna-warna, gambar suara, video, dan sesuatu yang instan (Nenden, 2020). Seorang guru harus mampu menggabungkan beberapa jenis media untuk disatukan penggunaannya dalam pembelajaran, yang 
dikenal dengan multimedia (Yunani, 2020). Salah satu aplikasi yang bisa digunakan adalah Macromedia Flash.

Macromedia Flash merupakan software yang dikembangkan oleh Adobe. Software ini dapat digunakan untuk animasi, game, dan aplikasi pengayaan internet yang dapat dijalankan pada perangkat yang memiliki aplikasi Adobe Flash Player (Wardani \& Setyadi, 2020). Macromedia Flash merupakan salah satu multimedia yang dapat membuat video, animasi, gambar, dan suara dengan cara yang mudah dan efektif. Dengan menggunakan multimedia, hal yang abstrak dapat dikonkretkan sehingga dapat ditampilkan ke hadapan siswa dan menarik minat belajarnya melalui berbagai bentuk animasi yang disajikan (Rahmi et al., 2019)

Pembelajaran yang dilakukan di MTs Al-Istiqomah Kiarapayung pada masa pandemi ini adalah pembelajaran konvensional yang dikombinasikan dengan media WhatsApp Group yang biasa digunakan siswa untuk berkomunikasi. Pembelajaran tersebut mengakibatkan siswa kesulitan dalam memahami materi.

Guru harus dapat menciptakan suatu pembelajaran yang bisa memberikan stimulus kepada siswa agar bisa lebih memahami materi lebih cepat sehingga dapat meningkatkan hasil belajar siswa yang masih kurang optimal dalam berpikir abstrak. Pemberian stimulus ini menggunakan teknologi dalam pembuatan media pembelajaran sehingga guru dapat mengomunikasikan gagasan dan konsep matematika. Oleh karena itu diperlukan model pembelajaran yang bisa memberikan stimulus kerja otak dengan memanfaatkan media digital dan intemet. Model pembelajaran tersebut adalah Brain Based Learning (BBL) berbantuan Macromedia Flash.

Menurut Jensen (Sapitra et al., 2019) menyatakan bahwa Brain Based Learning (BBL) adalah model pembelajaran yang diselaraskan dengan cara otak yang didesain secara ilmiah untuk belajar. Sejalan dengan yang dikemukakan oleh Saparina et al., (Herliandry et al., 2018) mengungkapkan model ini diselaraskan dengan cara otak dirancang secara alamiah untuk belajar, sehingga pembelajaran menjadi optimal. Penggunaan Macromedia Flash sebagai media pembelajaran, bermanfaat bagi guru sebagai alat bantu dalam menyiapkan bahan ajar dan menyelenggarakan pembelajaran. Media ini juga dapat memancing stimulus siswa agar dapat memanipulasi konsep-konsep serta dapat mengetahui bentuk nyata konsep matematika yang abstrak (Masykur et al., 2017). Oleh karena itu, tujuan penelitian ini adalah untuk mendeskripsikan pengaruh pembelajaran Brain Based Learning berbantuan Macromedia Flash terhadap peningkatan kemampuan komunikasi matematis siswa.

\section{METODE PENELITIAN}

Metode penelitian pada penelitian ini adalah metode eksperimen. Bentuk penelitian yang digunakan adalah quasi experimental dengan desain penelitian The Nonequivalent Pretest-Posttest Control Group Design. Desain penelitian ini digambarkan seperti berikut:

\section{$0 \times 0$}

0

Keterangan:

$\mathrm{X}=$ perlakuan/treatment yang diberikan (Brain Based Learning berbantuan Macromedia)

$\mathrm{O}=$ pretes/postes (Tes kemampuan komunikasi matematis)

Populasi dalam penelitian ini adalah seluruh siswa kelas VII di MTs Al-Istiqomah Kiarapayung tahun pelajaran 2020/2021. Sampel pada penelitian ini adalah siswa kelas VIIB sebagai kelas eksperimen dengan pembelajaran Brain Based Learning berbantuan Macromedia Flash dan kelas VIIA sebagai kelas kontrol dengan pembelajaran konvensional. Dalam penelitian ini pengambilan sampel dilakukan menggunakan teknik purposive sampling. Prosedur dalam penelitian ini yaitu sebelum dilakukan perlakuan, kemampuan komunikasi matematis masing-masing kelompok diukur dengan memberikan pretes. Pretes yang diberikan pada kelompok eksperimen sama dengan kelompok kontrol. Siswa pada kelompok eksperimen diberi perlakuan pembelajaran Brain Based Learning berbantuan Macromedia Flash, sedangkan siswa pada kelompok kontrol diberi pembelajaran konvensional. Setelah diberikan 
perlakuan, kemampuan komunikasi matematis masing-masing kelompok diukur dengan memberikan postes. Instrumen yang digunakan adalah instrumen tes berupa tes subjektif yang berbentuk uraian (essay) sebanyak 4 butir. Tes ini disusun berdasarkan indikator kemampuan komunikasi matematis yang hendak diukur. Tes diberikan kepada siswa sebelum dan sesudah perlakuan.

Data kuantitatif berupa skor hasil tes kemampuan komunikasi matematis siswa. Adapun data skor tes yang dimaksud adalah data N-gain. Data ini digunakan untuk membandingkan peningkatan kemampuan dua kelompok (kelas eksperimen dan kelas kontrol). Berikut ini rumus N-Gain ternormalisasi, yaitu:

$$
N \text {-Gain }=\frac{\text { skor postes-skor pretes }}{\text { SMI-Skor Pretes }}
$$

Hasil perhitungan N-gain kemudian diinterpretasikan dengan menggunakan klasifikasi dari Hake (1999) dengan kriteria indeks N-gain pada Tabel 1.

Tabel 1. Kriteria Skor Gain Ternormalisasi (g)

\begin{tabular}{cc}
\hline Skor & Kriteria \\
\hline $\mathrm{g} \geq 0,70$ & tinggi \\
$0,30 \leq \mathrm{g}<0,70$ & sedang \\
$\mathrm{g}<0,30$ & rendah \\
\hline
\end{tabular}

Teknik analisis yang digunakan dapat dilakukan dengan menggunakan langkah-langkah yaitu: Memberikan skor jawaban siswa, membuat tabel skor pretes dan postes, menghitung besarnya peningkatan (Data N-gain), prasyarat uji Statistik dan uji hipotesis dengan menggunakan uji t.

\section{HASIL DAN PEMBAHASAN}

Analisis skor N-gain kemampuan komunikasi matematis menggunakan data gain ternormalisasi, data gain ternormalisasi juga menunjukkan klasifikasi peningkatan skor siswa yang dibandingkan dengan skor maksimal idealnya. Rataan n-gain menggambarkan peningkatan kemampuan pemahaman komunikasi matematis siswa yang memperoleh pembelajaran Brain Based Learning berbantuan Macromedia Flash maupun yang memperoleh pembelajaran konvensional. Dengan menggunakan Microsoft Excel diperoleh:

Tabel 2. Nilai Rata-rata N-gain

\begin{tabular}{cccc}
\hline Kelas & Mean & $\mathbf{N}$ & Kriteria \\
\hline Eksperimen & 0.515 & 24 & sedang \\
Kontrol & 0.327 & 24 & sedang \\
\hline
\end{tabular}

Pada Tabel 2 dapat dilihat bahwa nilai rata-rata $\mathrm{N}$-gain untuk kelompok eksperimen adalah 0,51 termasuk dalam kriteria sedang sedangkan nilai rata-rata $\mathrm{N}$-gain untuk kelompok kontrol adalah 0,33 termasuk dalam kniteria sedang. Nilai rata-rata N-gain kelompok eksperimen lebih tinggi daripada nilai ratarata $\mathrm{N}$-gain kelompok kontrol.

Uji statistik yang diperlukan untuk membuktikan hipotesis yang menyatakan "terdapat perbedaan pengaruh pembelajaran Brain Based Learning berbantuan Macromedia Flash dan pembelajaran konvensional terhadap peningkatan kemampuan komunikasi matematis siswa" yaitu dengan memakai distribusi t (uji t) dengan menggunakan analisis uji t dalam software SPSS Statistics 23. Sebelum dilakukan uji tersebut, data skor n-gain harus memenuhi uji prasyarat normalitas dan homogenitas. Hasil pengolahan data uji Normalitas data N-Gain kelas eksperimen dan kelas kontrol disajikan pada Tabel 3. 
Tabel 3. Hasil Uji Normalitas Skor N-gain

\begin{tabular}{lccc}
\hline \multicolumn{1}{c}{ Kelas } & \multicolumn{3}{c}{ Shapiro-Wilk } \\
& Statistic & df & Sig. \\
\hline Eksperimen & 0,959 & 24 & 0,418 \\
Kontrol & 0,932 & 24 & 0,110 \\
\hline
\end{tabular}

Berdasarkan tabel uji normalitas Tabel 3, kelas eksperimen dan kelas kontrol memiliki nilai signifikansi lebih dari 0,05 sehingga dapat dikatakan $\mathrm{H}_{0}$ diterima. Hal ini menunjukkan bahwa data terdistribusi normal selanjutnya dilakukan uji homogenitas. Hasil pengolahan data uji homogenitas data NGain kelas eksperimen dan kelas kontrol disajikan pada Tabel 4.

Tabel 4. Hasil Uji Homogenitas Skor N-gain

\begin{tabular}{cccc}
\hline Levene Statistic & df1 & df2 & Sig. \\
\hline 2.154 & 1 & 46 & 0.149 \\
\hline
\end{tabular}

Kelas eksperimen dan kelas kontrol memiliki nilai signifikansi lebih besar dari 0,05. Hal ini menunjukkan bahwa data memiliki varians homogen Berdasarkan hasil uji normalitas dan homogenitas yang telah dilakukan, didapat kesimpulan bahwa kedua data berdistribusi normal dan homogen, maka pengujian selanjutnya menggunakan uji-t (Independent sample T-Test). Adapun hipotesisnya adalah sebagai berikut:

$$
\begin{array}{ll}
H_{0}: \mu_{1}=\mu_{2} & \begin{array}{l}
\text { Tidak terdapat perbedaan pengaruh pembelajaran Brain Based Learning } \\
\text { berbantuan Macromedia Flash dan pembelajaran konvensional terhadap } \\
\text { peningkatan kemampuan komunikasi matematis siswa }
\end{array} \\
H_{1}: \mu_{1} \neq \mu_{2} & \begin{array}{l}
\text { Terdapat perbedaan pengaruh pembelajaran Brain Based Learning berbantuan } \\
\text { Macromedia Flash dan pembelajaran konvensional terhadap peningkatan } \\
\text { kemampuan komunikasi matematis siswa }
\end{array}
\end{array}
$$

\begin{tabular}{|c|c|c|c|c|c|c|}
\hline & & \multicolumn{5}{|c|}{ t-test for Equality of Means } \\
\hline & & $t$ & $\mathrm{df}$ & $\begin{array}{c}\text { Sig. } \\
\text { (2-tailed) }\end{array}$ & $\begin{array}{c}\text { Mean } \\
\text { Difference }\end{array}$ & $\begin{array}{l}\text { Std. Error } \\
\text { Difference }\end{array}$ \\
\hline \multirow[t]{2}{*}{$\begin{array}{l}\text { Skor } \\
\text { Kemampuan }\end{array}$} & $\begin{array}{l}\text { Equal } \\
\text { variances } \\
\text { assumed }\end{array}$ & 2.466 & 46 & 0.017 & 0.188292 & 0.07637 \\
\hline & $\begin{array}{l}\text { Equal } \\
\text { variances } \\
\text { not } \\
\text { assumed }\end{array}$ & 2.466 & 43.944 & 0.018 & 0.188292 & 0.07637 \\
\hline
\end{tabular}

Hipotesis tersebut diuji dengan memakai distribusi t (uji t) dengan menggunakan analisis uji $t$ dalam software SPSS Statistics 23, diperoleh output pada Tabel 5.

Tabel 5. Hasil Uji Independent Sample T-Test

Dari output uji t di Tabel 5, ternyata nilai sig. nya adalah 0,017 dan nilai ini kurang dari $\alpha=0,05$. Hal ini menunjukkan bahwa $\mathrm{H}_{1}$ diterima, dan dapat dinyatakan bahwa terdapat perbedaan pengaruh pembelajaran Brain Based Learning berbantuan Macromedia Flash dan pembelajaran konvensional terhadap peningkatan kemampuan komunikasi matematis siswa.

Hasil penelitian menunjukkan bahwa pembelajaran Brain Based Learning berbantuan Macromedia Flash berpengaruh lebih tinggi terhadap peningkatan kemampuan komunikasi matematis siswa daripada pembelajaran konvensional. Hal ini ditunjukkan dengan skor $\mathrm{N}$-gain siswa yang menerapkan pembelajaran Brain Based Learning berbantuan Macromedia Flash sebesar 0,51 (kategori 
sedang), lebih tinggi dari pada siswa yang mendapatkan pembelajaran konvensional sebesar 0,33 (kategori sedang). Hasil tersebut memberikan gambaran bahwa pembelajaran dengan Brain Based Learning berbantuan Macromedia Flash dapat mengembangkan kemampuan komunikasi matematis siswa. Temuan ini sejalan dengan hasil penelitian Setiani (2018) bahwa hasil belajar matematika siswa yang menggunakan pembelajaran Brain Based Learning lebih baik dari pada pembelajaran konvensional dan penelitian Sari et al., (2019), bahwa ada perbedaan yang signifikan antara kemampuan siswa yang memperoleh pembelajaran Brain-Based Learning dengan siswa yang memperoleh pembelajaran konvensional.

Pembelajaran Brain Based Learning berbantuan Macromedia Flash dalam penelitian ini dirancang sedemikian rupa sehingga siswa dapat memanipulasi konsep-konsep serta dapat mengetahui bentuk nyata konsep matematika yang abstrak melalui media visual Macromedia Flash. Macromedia Flash dibangun dengan flash yang terdiri dari gambar, teks, animasi sederhana, video, dan efek khusus lainnya. Aplikasi ini mampu membuat animasi yang menarik dan interaktif sehingga kegiatan pembelajaran menjadi lebih menyenangkan dan tidak membosankan. Dalam penerapannya, model Brain Based Learning memiliki tahap-tahap pembelajaran yaitu (a) Tahap pra-pemaparan; (b) Tahap persiapan; (c) Tahap inisiasi dan akuisisi; (d) Tahap elaborasi; (e) Tahap inkubasi dan pengkodean memori; (f) Tahap verifikasi dan pengecekan keyakinan; (g) Tahap selebrasi dan integrasi.

Pada tahap pra-pemaparan dimana guru mengondisikan lingkungan belajar, tahap kedua persiapan yaitu guru memberikan penjelasan awal mengenai materi yang akan dipelajari dan kaitannya dengan kehidupan nyata, tahap ketiga inisiasi dan akuisisi yaitu guru menyajikan dan menjelaskan materi dengan bantuan media visual Macromedia Flash yang dilengkapi dengan gambar dan animasi disetiap materi, tahap keempat elaborasi yaitu guru mengarahkan peserta didik untuk menganalisis, menalar dan mendiskusikan masalah agar dapat menuliskan penyelesaian dari permasalahan pada LAS, tahap kelima inkubasi dan pengkodean memori yaitu guru melakukan peregangan dan relaksasi terhadap peserta didik sambil menonton video motivasi atau diberikan brain gym yang dapat melatih konsentrasi dan fokus pada otak melalui Macromedia Flash dan kemampuan guru memberikan beberapa pertanyaan sederhana terkait dengan materi yang dipelajari, tahap keenam verifikasi dan pengecekan keyakinan yaitu guru memberikan soal tes individu terhadap peserta didik dan kemampuan guru membimbing peserta didik untuk menyimpulkan hal-hal yang telah dipelajari, dan pada tahap ketujuh selebrasi dan integrasi yaitu guru memberikan penghargaan kepada siswa yang aktif dalam kegiatan pembelajaran dan kemampuan guru menanamkan semua arti penting dari kecintaan terhadap belajar (Oktaviana \& Rohendi, 2017).

Tingkat kemampuan guru selama proses pembelajaran dengan model Brain Based Learning berbantuan Macromedia Flash sangat mendukung dalam meningkatkan kemampuan komunikasi matematis siswa. Mengomunikasikan merupakan salah satu kegiatan wajib dalam pembelajaran matematika, seperti menyampaikan hasil pengamatan, kesimpulan berdasarkan hasil analisis baik secara lisan, tulisan, maupun media lainnya, dan menyajikannya dalam bentuk bagan, diagram, atau grafik.

Uraian tersebut menegaskan bahwa pembelajaran matematika dengan pembelajaran Brain Based Learning berbantuan Macromedia Flash dapat meningkatkan kemampuan komunikasi matematis siswa. Data yang diperoleh dari hasil penelitian ini secara umum membuktikannya. Selisih perbedaan peningkatan kemampuan komunikasi matematis pada kelas eksperimen yang menerapkan pembelajaran Brain Based Learning berbantuan Macromedia Flash dengan kelas kontrol mencapai hingga $18 \%$.

\section{KESIMPULAN}

Berdasarkan hasil analisis, temuan, dan pembahasan yang telah disajikan, diperoleh simpulan bahwa terdapat perbedaan pengaruh pembelajaran Brain Based Learning berbantuan Macromedia Flash dan pembelajaran konvensional terhadap peningkatan kemampuan komunikasi matematis siswa dan berdasarkan rata-ratanya, pembelajaran Brain Based Learning berbantuan Macromedia Flash berpengaruh lebih tinggi terhadap peningkatan kemampuan komunikasi matematis siswa daripada pembelajaran konvensional. 


\section{REKOMENDASI}

Berdasarkan pada penelitian yang telah dilakukan, dipaparkan beberapa rekomendasi dari peneliti diantaranya yaitu:

1. Pembelajaran Brain Based Learning berbantuan Macromedia Flash bisa dijadikan salah satu alternatif pembelajaran untuk meningkatkan kemampuan komunikasi matematis siswa.

2. Sebaiknya LAS, musik, brain gym, media ataupun bahan ajar lainnya dibuat beragam dan semenarik mungkin sehingga tidak menimbulkan kebosanan siswa.

\section{UCAPAN TERIMAKASIH}

Peneliti mengucapkan terimakasih kepada Progam Studi Pendidikan Matematika Fakultas Keguruan dan IImu Pendidikan Universitas Galuh, Bapak Oman Somantri, S.H.I selaku kepala madrasah, dan lin Rumniingsih, S,Pd.I selaku guru matematika kelas VII di MTs Al-Istiqomah Kiarapayung yang telah memperkenankan dan membantu penulis dalam melakukan penelitian.

\section{DAFTAR PUSTAKA}

Deswita, R., \& Kusumah, Y. S. (2018). Peningkatan Kemampuan Komunikasi Matematis Siswa Melalui Model Pembelajaran CORE dengan Pendekatan Scientific. Edumatika : Jurnal Riset Pendidikan Matematika, 1(1), 35. https://doi.org/10.32939/ejrpm.v1i1.220

Hendriana, B. (2018). Identifikasi Kemampuan Komunikasi Matematis dan Gaya Belajar Siswa. Seminar Nasional Pendidikan Matematika 2018, 01(1), 477-484.

Herliandry, L. D., Harjono, A., \& 'Ardhuha, J. (2018). Kemampuan Berpikir Kritis Fisika Peserta Didik Kelas X dengan Model Brain Based Learning. Jurnal Penelitian Pendidikan IPA, 5(1). https://doi.org/10.29303/jppipa.v5i1.166

Masykur, R., Nofrizal, N., \& Syazali, M. (2017). Pengembangan Media Pembelajaran Matematika dengan Macromedia Flash. Al-Jabar: Jurnal Pendidikan Matematika, 8(2), 177. https://doi.org/10.24042/ajpm.v8i2.2014

Muslimahayati, M. (2019). Kemampuan Komunikasi Matematis Siswa dengan Pendekatan Pembelajaran Matematika Realistik bernuansa Etnomatematika (PMRE). Jurnal Pendidikan Matematika RAFA, 5(1), 22-40. https://doi.org/10.19109/jpmrafa.v5i1.3773

Nenden. (2020). Peningkatan Kompetensi Pedagogik Guru SD Negeri Karsamenak Kota Tasikmalaya melalui Penggunaan Media ICT (Information and Communication Technology). J-KIP (Jurnal Keguruan dan IImu Pendidikan), 1 (2), 63-70.

Oktaviana, S. E., \& Rohendi, E. (2017). Model Brain Based Learning (BBL) untuk Meningkatkan Pemahaman Siswa. A n t o l o g i U P I, 5(1), 169-178.

Rahmi, M. S. M., Budiman, M. A., \& Widyaningrum, A. (2019). Pengembangan Media Pembelajaran Interaktif Macromedia Flash 8 pada Pembelajaran Tematik Tema Pengalamanku. International Journal of Elementary Education, 3(2), 178. https://doi.org/10.23887/ijee.v3i2.18524

Saparudin, D., \& Effendi, K. (2019). Kemampuan Komunikasi Matematis pada Peserta Didik SMP Kelas VII terhadap Materi Bangun Dimensi Tiga. Prosiding Sesiomadika, 2(1c), 687-694.

Sari, S. L., Hidayati, D. W., \& Wahyuni, A. (2019). Penerapan Strategi Brain-Based Learning 
Berbantuan Geogebra Terhadap Kemampuan Berfikir Kreatif Siswa. Square: Journal of $\begin{array}{llll}\text { Mathematics and } \quad \text { Mathematics } & 13 .\end{array}$ https://doi.org/10.21580/square.v1i1.4038

Setiani, A. (2017). Penerapan Model Pembelajaran Brain Based Learning. Penerapan Model Pembelajaran Brain Based Learning, 2(1), 451-460. https://doi.org/10.175 09/jpi.v2i1.10680

Sapitra, D., Yulianti, Y., \& Juwita Agustina, W. (2019). Penerapan Model Brain Based Learning Bernuansa Lingkungan Sekitar dalam Meningkatkan Pemahaman Siswa Pada Pembelajaran Ipa Di Kelas V Sekolah Dasar. 4, 1-9.

Wardani, K. W., \& Setyadi, D. (2020). Pengembangan Media Pembelajaran Matematika Berbasis Macromedia Flash Materi Luas dan Keliling untuk Meningkatkan Motivasi Belajar Siswa. Scholaria: Jurnal Pendidikan Dan Kebudayaan, 10(1), 73-84. https://doi.org/10.24246/j.js.2020.v10.i1.p73-84

Yunani, Y. (2020). Penggunaan Multimedia dalam Pembelajaran PAI untuk Meningkatkan Hasil Belajar Siswa Kelas IX C SMP Negeri 2 Ciamis. J-KIP (Jurnal Keguruan dan IImu Pendidikan), 1 (2), 55-62. 